\title{
LIGHT CURING UNITS: TIPS FOR ORTHODONTISTS
}

Z. Radzi, N.A. Yahya, N. Zamzam, D.J. Wood. Light curing units: Tips for orthodontists. Annal Dent Univ Malaya 2004; 11: 13-23.

\begin{abstract}
Choosing the right light-curing unit can be a very difficult task for some orthodontists. Currently, there are various types of light curing units available in the market with various trade names and specifications. Most of the time information regarding light curing units is obtained from advertisements, websites or manufacturers' catalogues. Sometimes such information can be misleading. This article attempts to provide several tips for orthodontists in selecting light curing units.
\end{abstract}

Key words: light curing units, composite resin, orthodontics.

\section{INTRODUCTION}

Currently, there are various types of dental light curing units available in the market. Sometimes, it is rather difficult for clinicians to choose which lightcuring unit will work best to suit their needs. Most of the clinicians rely on information given by manufacturers or through advertisements. This article attempts to provide information which can be useful for the clinician in choosing the right lightcuring unit. This paper discusses light curing units which are currently used in orthodontics and no attempt has been made to generalize their use in other fields of dentistry.

Before one can choose the right light-curing unit, a few questions need to be asked as follows:

- What is the use of a light-curing unit?

- How does a light curing unit influence the polymerization process?

- What are the aims in developing light-curing unit?

- What are the basic components of light curing units?

- What are the types of light-curing units that are available in the market?

- What are the advantages and disadvantages of different light curing units?

- How can the performance of the light-curing unit be measured?

- What practical tips are useful to the orthodontist?
Z. Radzi1, N.A. Yahya ${ }^{2}$, N. Zamzam ${ }^{1}$, D.J. Wood ${ }^{3}$

IDepartment of Children's Dentistry and Orthodontics

${ }^{2}$ Department of Conservative Dentistry Faculty of Dentistry, University of Malaya 50603 Kuala Lumpur, Malaysia

${ }^{3}$ Department of Restorative Dentistry Leeds Dental Institute, University of Leeds Clarendon Way, LS2 9LU

Leeds, United Kingdom

Corresponding author - Zamri Radzi

\section{WHAT IS THE USE OF A LIGHT-CURING UNIT?}

In orthodontics, the clinician can either use the chemically or light cured composite to bond the brackets onto teeth. Most of the composite resins contain monomer, inorganic filler, inhibitors, stabilizers, pigments and initiators (1). The most commonly used initiator is camphorquinone. The light cured composite required some form of light produced by the light-curing unit to activate the polymerization process (2).

The polymerization of the light-cured composites depends completely on an adequate delivery of light energy. Usually, the light required for curing is between 360 to $500 \mathrm{~nm}$ with a maximum of 460 to $470 \mathrm{~nm}$. For camphorquinone, light at wavelength of $470 \mathrm{~nm}$ is essential (3). Polymerization is initiated and sustained when the curing light intensity is sufficient to maintain camphorquinone, the lightsensitive agent in the composite in its excited state. Only when the camphorquinone is in this excited state, then, will it react with an amine-reduction agent to form free radicals, thus initiating the resin's polymerization (1). Depending on the mass of the material, a certain power density $\left(\mathrm{mW} / \mathrm{cm}^{2}\right)$ is required to decompose the initiator $(3,4)$.

According to the ISO specification for light curing unit, the energy output must be measured only for the spectral region of 460 to $500 \mathrm{~nm}(5,6)$. It must be emphasized, however, that not all resin-based composite products use camphorquinone as an initiator. Some other composite resin uses BAPO (bis acryl phosphinoxide) as an initiator. Therefore a wide spectrum of light might be a safe approach if many different products are used (3). 


\section{HOW DOES A LIGHT CURING UNIT INFLUENCE THE POLYMERIZATION PROCESS?}

There are several factors related to light curing that can influence the polymerization process and the strength of the material such as $(7-10)$ :

- Intensity of the light

- Curing time

- Depth of cure

\section{WHAT ARE THE AIMS IN THE DEVELOPMENT OF A LIGHT-CURING UNIT?}

The aims in the development of a light curing unit are to produce the units that are powerful, able to cure the composite with reduced curing time and able to avoid under curing (1). In the clinical situation, under curing can occur if the light (7-10):

- is not sufficiently close to the surface of the material being polymerized;

- is of insufficient intensity;

- is attenuated by passage through a bracket;

- is of the incorrect wavelength.

\section{WHAT ARE THE BASIC COMPONENTS OF LIGHT CURING UNITS?}

The basic components of light curing units are as follows (Figure 1): hand piece, hand piece push button, nose cone, light guide, eye shield, power module, power cord, main switch, indicator light, fuse, plug, bulb, filter, and fan $(11,12)$.
Some of the light-curing units have integrated curing meter, microprocessor and battery charger (13).

\section{WHAT ARE THE TYPES OF LIGHT-CURING UNITS THAT ARE AVAILABLE IN THE MARKET?}

\section{Ultra-Violet Light Curing unit}

Ultra-Violet light curing unit was the first to be used in curing light cured composite. The technology came from other industry such as ink, paint and coating materials that used the ultraviolet in photopolymerization process $(14,15)$. This unit utilized the polymerization process of a composite that can be accomplished by the energy derived from ultra-violet light. The wavelength is in the range of 364-367 nm (17). Ultra-violet systems enjoyed popularity for a time because of its common sets. Later, it was found that this light could cause damage to the eye. Since then the use of this unit in clinical practice has been discarded and are no more available in the market (14).

\section{Halogen Light Curing Unit}

Halogen light curing unit has been innovated to replace the ultra-violet light curing unit (14). This unit is able to produce flux in the range of $400-500$ $\mathrm{nm}$ that is within the camphorquinone spectrum (17). Most of the units use tungsten filament halogen lamps that incorporate a blue filter. This filter is important in producing the broad range of wavelength within $400-500 \mathrm{~nm}$ regions. The light is directed using a wave-guide such as a fused glass bundle $(18,19)$. It is able to produce the energy level up to $300 \mathrm{mV}$ (20). The amount of time required to cure the composite

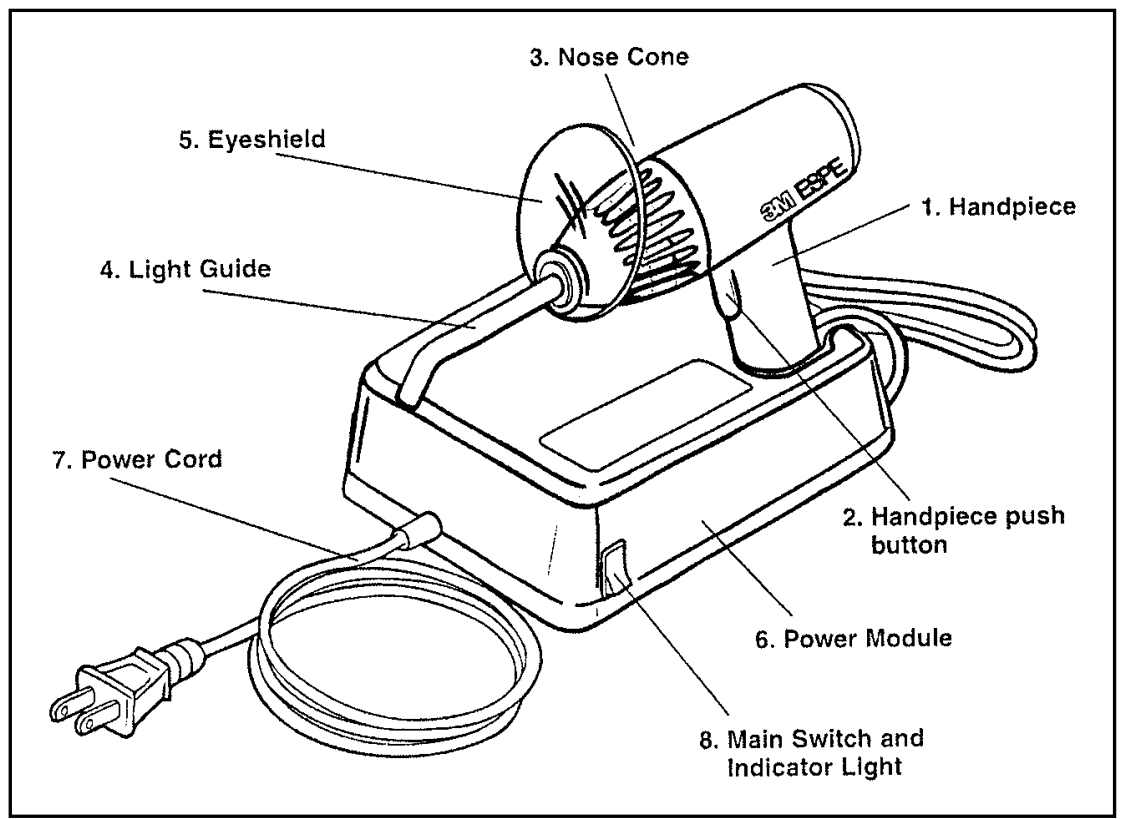

Figure 1: Basic components of a light curing unit. 
underneath metal brackets is 40 seconds per tooth (21).

\section{High Performance Halogen Curing Light}

High Performance Halogen light curing unit has been developed to overcome the problem of conventional halogen light that requires a longer time to cure the orthodontic composite. This unit has a special tungsten quartz halogen optibulb whose performance does not degrade with time. It also has an $8 \mathrm{~mm}$ light guide, which emits a full spectrum light filtered as blue with a range of 400 to $505 \mathrm{~nm}$. It cures under metal brackets in eight seconds and under ceramic brackets in five seconds. This light has boost mode, which increases the light output to $1,000 \mathrm{mWatt} / \mathrm{cm}^{2}$ in 10 -second cycles with a five second beep (22-24). This will allow the composite under metal bracket to be cured in five seconds (25).

\section{Adaptor Light Guide}

A modification of light guide has been designed as a direct replacement for the original light guide of the halogen curing light. This guide has been designed using computer technology. It has a unique flat tip with maximum tapered optic fibers. It is able to increase the light output 2.5 times more than the original light guide used with halogen light curing unit. The surface area is about $28 \mathrm{~mm}^{2}$. The light output ranges from 880 to $1120 \mathrm{~mW} / \mathrm{cm}^{2}$. The guides are currently available in various sizes and shapes (Figure 2). It can be fitted to almost all halogen light curing units. The idea of this light guide is to save the cost of buying a new expensive light-curing unit.
The same halogen light-curing unit can be used with improved curing time (26-29).

\section{Plasma Arc Light Curing Unit}

This unit has been developed after the technology used by The United States National Aeronautics and Space Association (NASA) in aeronatical engineering. The plasma arc light system has filters that are able to narrow the spectrum of visible light to a band centred at $470 \mathrm{~nm}$. This wavelength could be used for activation of the camphorquinone (30). It has two electrodes with a large voltage potential that are able to ionize xenon plasma gas to emit the light. These lights have an energy level of $900 \mathrm{mV}$, which is much higher than halogen lights. This allows curing times to be as short as possible. This unit will take only two seconds to cure the composite underneath the metal bracket (31).

\section{Blue Light Emitting Diode (Blue LED) Curing Unit}

The breakthrough in semiconductor technology has led to the use of LED in curing light cured composites $(32,33)$. LED is a solid-state light source. It is manufactured by layering the metal organic chemical vapour deposition of different semiconductor materials on top of another in special films (33).

This unit uses indium gallium nitrate technology. It can generate photons of a particular wavelength by varying the band gap. A wide band gap material produces high-energy photons near the blue region of the visible spectrum (34). As current flows through the semiconductor chips, electrical energy is

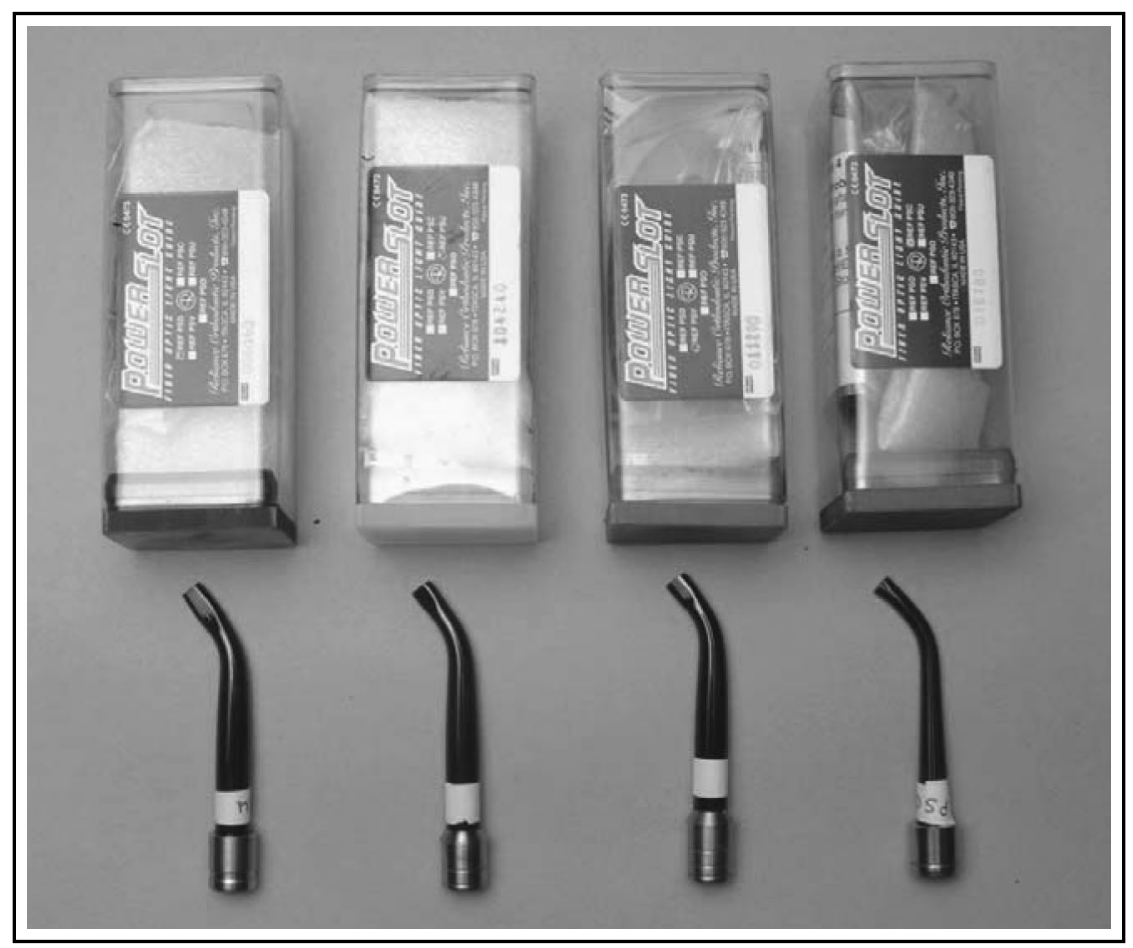

Figure 2: Different types of adaptor light guide. 
converted directly into light. Little energy is emitted as heat. The result is a stable, efficient and long lasting output of blue light. The spectrum of light produced is in the range of 430 to $490 \mathrm{~nm}(35,36)$. The narrow spectral mission of the LED encompasses the spectral absorption of camphorquinone at 470 $\mathrm{nm}$ (35). This unit can generate a curing light of density of 400 to $2000 \mathrm{~mW} / \mathrm{cm}^{2}$ depending on the types and products $(11-13,35,36)$. It is able to cure the orthodontic composite in between 10 to 40 seconds.

\section{Argon Laser Curing Unit}

Argon laser curing unit has utilized the laser technology which provides sources that emit high intensity light within the energy band required by the initiator in light cured composites (18). Laser light has been described as consisting of a single, narrow band of waves traveling in parallel and in phase spatially and temporally $(37,38,40)$. The argon laser is monochromatic and emits light over a narrow band of wavelengths in the blue-green spectrum. It operates within a combined bandwidth that encompasses $42 \mathrm{~nm}$ (between 454nm and 496nm) of the visible light spectrum. It provides high output energy at $488 \mathrm{~nm}$ for the rapid polymerization of dental composites $(18,39)$, The intensity of light produced by this unit approaches $800 \mathrm{~mW} / \mathrm{cm}^{2}$. Argon laser's waves are coherent; the photons are in phase with one another and do not collide as they do in halogen light. The time required to cure the orthodontic composite is five seconds (18,37-40).

Basic specifications of light-curing units which are available in the market are summarized in Table 1.

\section{WHAT ARE THE ADVANTAGES AND DISADVANTAGES OF DIFFERENT LIGHT CURING UNITS?}

\section{Ultra Violet Light Curing Unit}

The use of this light-curing unit has been abandoned. It was time consuming, as a 90 seconds application must be given to each bracket. In addition, ultra-violet is poorly transmitted by tooth substance, plastic or metal brackets (16). Also, there has been some concern about the possible harmful effects of prolonged exposure to ultra-violet radiation (41). It has the potential to cause retinal damage and the possibility of selectively altering the oral microflora through exposure of ionizing radiation $(14,41)$.

\section{Halogen Light Curing Unit}

Halogen light curing unit uses most of its energy to heat a tungsten filament until it glows which then creates the light. Only one percent of the total energy output is converted into light; the remainder is generated as heat (42). Therefore one of the disadvantages is heat production that can cause blistering of expensive light filters and discolouration of the reflectors. This will lead to a decrease in blue flux and a reduction in curing effectiveness (42). A great deal of heat produced by halogen curing lamps requires intensive fan cooling, which in turn may disperse any bacterial aerosol present in the patient's mouth (43). The cooling fan can be noisy and bulky (33). It was found that halogen bulbs last only up to 50 hours and should be replaced every six months $(44,45)$.

To overcome some of the above problems the unit has been designed to have continuous operation and programmed cycles. One program is called a stepping function, which cycles the light on and off to reduce possible overheating of the tooth (17).

\section{High Performance Halogen Light Curing Unit}

The light produced by this unit is intense and the tip of the guide may occasionally cause some discomfort to the skin or mucosa (46). The advantage of this unit is that it can cure the composite with reduced curing time (25).

\section{Adaptor Light Guide}

The disadvantage of this adaptor is that its usage relies heavily on the halogen-curing unit. Therefore, whatever problems encounter by the halogen-curing unit may have an effect on its performance (47).

Among the advantages are that it can be sterilized either chemically or in an autoclave, it can cure the composite with reduced time and it is

Table 1. Basic specifications of light-curing units that are available in the market

\begin{tabular}{lccc}
\hline Type of light curing unit & $\begin{array}{c}\text { Time required to } \\
\text { cure a metal bracket }\end{array}$ & Light output & Spectrum of light \\
\hline Halogen Light & 40 seconds & $300 \mathrm{mV}$ & $400-500 \mathrm{~nm}$ \\
High performance Halogen Light & 8 seconds & $1000 \mathrm{mV}$ & $400-505 \mathrm{~nm}$ \\
Adaptor light guide with halogen light & 10 seconds & $880-1120 \mathrm{mV}$ & $400-500 \mathrm{~nm}$ \\
Plasma arc light & 2 seconds & $900 \mathrm{mV}$ & $430-490 \mathrm{~nm}$ \\
Blue LED & $10-40$ seconds & $400-2000 \mathrm{mV}$ & $430-490 \mathrm{~nm}$ \\
Argon Laser & 5 seconds & $800 \mathrm{mV}$ & $454-496 \mathrm{~nm}$ \\
\hline
\end{tabular}


economical since the adaptor is cheaper than other light curing units (27).

\section{Plasma Arc Light Curing Unit}

These lights have an energy level of $900 \mathrm{mV}$, which is much higher than halogen lights (20). The plasma bulb generates considerable heat and therefore requires a large fan to cool it off during and after each burst of light (25).

Although the light is more intense but the spectrum of the light is rather narrow. Therefore, it is important to match the spectrum of a plasma arc light to the product being used otherwise, the materials may be left undercured (26).

One of the concerns that surround the plasma arc bulb is the potential increase in pulpal temperature by as much as $6^{\circ} \mathrm{C}$ when tested on a molar tooth (48). It has been suggested that a $5^{\circ} \mathrm{C}$ to $6{ }^{\circ} \mathrm{C}$ increase in pulpal temperature could result in irreversible pulp damage $(46,47)$. The most significant advantage is that it can cure the composite in two seconds (51).

\section{Blue Light Emitting Diode (LED) Curing Unit}

Blue Light Emitting Diodes (LED) curing unit has an advantage over halogen light curing unit in that it is inexpensive. It offers a very long-lasting and relatively stable output of visible blue flux. The LED unit has no bulb or filter that requires maintenance (33). Therefore it can avoid any attenuation of power output due to degradation. It is an efficient converter of electrical power into visible blue flux. It does not generate the large quantities of heat as in the halogen light-curing unit. It has a potential of a lifetime over 10,000 hours and can be subjected to mechanical shocks and vibration (33). Another advantage of LED technology is the cordless operation (Figure 3). It consumes little power in operating $(33,52)$. Some of the units have an integrated microprocessor to control the light intensity. This ensures the light intensity remains constant at all times, irrespective of whether the battery is freshly charged or already running down. These units also have standard and exponential mode. Exponential mode provides constant full light intensity throughout the curing and the exponential mode on the other hand increases the light intensity exponentially $(1,12,13)$. The exponential mode will allow 'soft start polymerization' that has been demonstrated to be advantageous with regard to stress development and marginal adaptation (22).

Most of these units do not have integrated cooling fans. However, a number of newer LED curing units have been improved to increase the light intensity. As a consequence, they produce large quantities of heat. Therefore, they require built-in cooling fans. This can then be a disadvantage as the cooling fan can be noisy and bulky (33).

\section{Argon Laser Curing Unit}

One of the advantages of this unit is the ability to achieve a thorough cure with reduced curing time; as a result, the physical properties of the composites are enhanced. These could be due to the laser's specific and consistent wavelengths (53-56). The light is emitted without any wasted or unusable emissions (37). The total curing time is 75 percent shorter than those with halogen light.

In terms of adverse effects, it has been stated that no apparent pulp or enamel damage is expected at the energy level used for curing (57).

\section{HOW CAN THE PERFORMANCE OF THE LIGHT-CURING UNIT BE MEASURED?}

The light produced by the light-curing unit can be measured either directly or indirectly. It can be measured directly using curing radiometer and

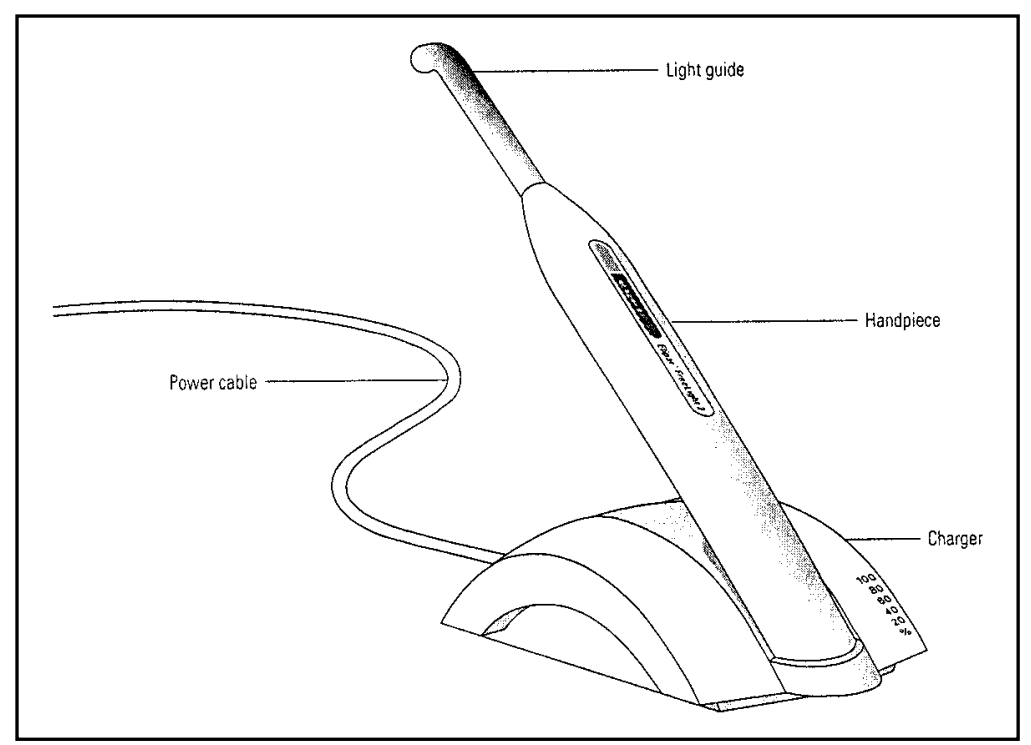

Figure 3: Blue LED Light Curing Unit. 
indirectly, in terms of the bond strength of the materials cured by each unit in clinical trials or laboratory studies. The light-curing unit should be able to cure the composite to the optimum bond strength. In the vast majority of published papers, bond strength is defined as the debonding force divided by the area of the bonded interface and it has been reported in numerous units: $\mathrm{MPa}, \mathrm{Kg} / \mathrm{cm}^{3}, \mathrm{Mn} /$ $\mathrm{mm}^{2}$ and $\mathrm{lb} / \mathrm{in}^{2}$ or Psi (77). The required bond strength required for orthodontic bonding is not clearly defined. Bond strength of $60-80 \mathrm{~kg} / \mathrm{cm}^{3}(6-8$ $\mathrm{MPa}$ ) has been suggested as optimum by Reynolds in 1975 (58).

Various studies have been carried out to investigate the effect of different light curing units on the bond strength:

\section{Halogen Light Curing unit}

Halogen curing light unit has been used as a control or standard since it is proven that it can produce a clinically acceptable bond strength. It is widely accepted as a safe mode of curing composites (59).

\section{High Performance Halogen Light Curing Unit}

Usumez et al. (2004) found that high performance halogen light polymerize composite resin in much shorter times than do the halogen light without a significant loss in strength and hardness (60).

\section{Adaptor Light Guide}

Frost et al. (1997) concluded that with the larger size of the light guide a significantly shorter total bonding time for each patient was required. They found that the elliptical light guide in combination with standard halogen light unit of sufficient quality gave bonding results similar to the halogen lightcuring unit. However, this light guide offered the clinician with a reduced chair side time (29).

Radzi et al. (2002) found that brackets bonded with 'Power slot', a special light curing guide, produced equivalent bond strength to a halogen light curing unit and it offers potential for significant time saving due to faster curing time (26). This is in agreement with the study carried out by Evan et al. in 2002 (61).

\section{Plasma Arc Light}

Ishikawa et al. (2001) recommended the use of plasma arc light as it has significantly reduced the curing time without affecting the shear bond strength (62). Several investigators were in agreement with Ishikawa et al. (2001). They found no statistically significant difference between the bond strengths of the composite cured with plasma light and halogen light (63-68). However most of these studies are laboratory based.

A clinical study conducted by Sfondrini et al. (2004) also revealed that plasma arc lights can be considered as an advantageous alternative to halogen light curing, because it enables the clinician to reduce the curing time of composite without affecting the bond strength (69).

\section{Blue Light Emitting Diode (LED) Curing Unit}

Dunn and Taloumis (2002) suggested that additional clinical studies should be performed before routine use of the commercial LED light curing unit can be recommended for orthodontic bonding (70). One of the most interesting finding by Radzi et al. (2002) was that even though the mean bond strength produced by the first generation of Blue LED curing unit was below the minimum values, it however had the highest Weibull Modulus. It has been suggested that even though the strength is inadequate, by far, it is the most reliable. In the future the development of Blue LED will lead to a more powerful and reliable unit (26).

A recent study by Swanson et al (2004) on shear bond strength of orthodontic brackets bonded with light emitting diode-curing unit at various polymerization times found that all experimental groups recorded mean shear bond strength greater than $8 \mathrm{MPa}$, even with a 10 seconds cure (33). It is therefore of importance as Blue LED light has gone through tremendous development since it was first introduced.

\section{Argon Laser Curing Unit}

An in vitro study of the effect of argon laser irradiation on the shear bond strength of orthodontic brackets, found that the argon laser could be used to irradiate brackets, achieving bond strength similar to those attained with a halogen light cure. Furthermore argon laser irradiation of brackets previously cured with a halogen light further increased bracket bond strength (71).

Lalani et al. (2000), in their study on the curing time and shear bond strength of polymerization with an argon laser, found that at $300 \mathrm{~mW}$ of power the argon laser required 87.5 percent less time than a halogen light curing unit to obtain a similar in vitro bond strength (72).

Weinberger et al. (1997) and Husson (2000) are in agreement with the above studies. They found no significant difference between the bond strengths produced by argon laser and the halogen light $(73,74)$.

\section{WHAT PRACTICAL TIPS ARE USEFUL TO THE ORTHODONTIST?}

Success in using light-cured composites relies heavily on proper curing time and intensity. Many factors affect the performance of curing light sources. Poor quality of the light-curing unit may lead to inadequate setting of the composite resin. Hence, the clinician should choose a light source with adequate 
curing power and test its output periodically to ensure that it has maintained proper intensity (75). In general, most commercially available light curing units will polymerize most light-cured composites to a depth of $3 \mathrm{~mm}$, though some systems are more efficient than others. Those units are halogen, high performance halogen, Argon laser and Plasma arc light curing unit. Only the newer generation of Blue LED light curing units are able to perform to the required standard.

It is important for the clinician to know the type of composite resin and initiator used. It is crucial because the range of the light spectrum required by the initiator should lie between the ranges of the light produced by the light-curing unit. Otherwise it may leave the composite partially cured or under cured.

It is also important for the clinician to know the balance between reduced curing time and the adverse effect produced by the light-curing unit such as heat, shrinkage and microleakage. Microleakage around the bracket may cause enamel decalcification $(67,80)$. Reduced curing time from 40 seconds to five seconds will reduce the total amount of curing time to 800 percent. It simply means that the busy orthodontists are able to see more patients in one day. However, any adverse effects such as decalcification due to orthodontist's negligence may lead to litigation.

It will be useful to compare the price of each light-curing unit. The price may vary from one trade name to another trade name even though the specifications are similar. Adaptor light guide can be an economical choice for the clinician who already owns a halogen light curing unit.

It is also important to ensure that the local supplier can provide the after sales maintenance. The unit such as the halogen light requires routine maintenance. Otherwise, the light output that it produces may not meet the required standard. Barghi et al (1994) evaluated the intensity output of 209 light curing units in 122 dental practices. They found that 45 percent had output below $300 \mathrm{~mW} / \mathrm{cm}^{2}$ and 65 percent had output less than $200 \mathrm{~mW} / \mathrm{cm}^{2}(77)$. This value is far below the output recommended by the ISO and most of the resin composite manufacturers $(77,78)$. The unit that has 'soft start mode' can be of advantage as this method does reduce the conversion rate and polymerization stress as well as enhance the potential for maintaining marginal integrity (22).

It is better to buy the unit that has least need for maintenance as compared to the one with higher maintenance. This must be coupled with good quality and the ability to produce optimum light intensity. The blue LED unit has the least maintenance while the halogen light curing unit requires heavy maintenance.

It will be useful to have a unit that has an integrated curing meter. This will allow the clinician to check the curing light emitting power every time it is used.

\section{DISCUSSION}

It has been shown that almost all light curing units are able to produce the bond strength above the minimum requirement of 6-8 $\mathrm{MPa}$ as suggested by Reynolds. However, the data must be interpreted with caution because most of the studies were conducted in the laboratories and would have shortcomings in the clinical setting (79). Also, most of the studies were conducted in a non-standardized manner; therefore direct comparison from one study to another study is difficult (80-85). Some studies did not control the distance between the light curing tip and the composite. In the future, bond strength studies should be directed towards clinical trials with special emphasis on survival rates rather than purely laboratory studies which do not simulate the clinical condition. A systematic review or meta analysis of prospective randomized controlled clinical trials will provide better evidence on the efficacy of these light curing units. Meta analysis of the currently available literature can be criticized, as it has various qualities and pooling together of the heterogeneous studies (86).

One needs to bear in mind that most research has been carried out using newly bought light-curing units. In clinical practice, many factors may affect the performance of light curing units. Long-term use of the light-curing unit will affect the condition of the bulb, reflector, filter and light guide. These are the factors, which can be checked visually (87-89). Performance of the power supply also affects light output but is not easily evaluated. Other factors, such as the distance, orientation of light source, reflector's backing, mould size and optical configuration, may also affect polymerization and depth of cure (87-93).

In summary, a curing light with an intensity of $300 \mathrm{~mW} / \mathrm{cm}^{2}$ will effectively cure most composite shades within the manufacturers' recommended times (87). The International Organization for Standardization (ISO) also recommended the intensity of $300 \mathrm{mw} / \mathrm{cm}$ to be used in clinical practice (5). Some of the information on various types of light curing units had been summarized in Table 1.

Another mode of curing that has been introduced in other fields of dentistry, but has not been utilized in orthodontics, is microwave curing. It has been suggested by Yunus et al. (1994) that denture based products can be polymerized with conventional microwave oven as a source of curing energy (94). This type of energy could be useful in curing the bonded brackets using 'Indirect Technique'. This technique is usually carried out in the laboratory.

\section{CONCLUSION}

The clinical goals of curing are short irradiation time in combination with high and uniform conversion 
throughout the whole composite resin and low shrinkage. This can be achieved using a light curing unit that can produce optimum bond strength with reduced curing time, less side effects and hazards to both operator and patient. Cheap, portable, high quality and durability are the ideal criteria of a lightcuring unit. Therefore, it is essential for clinicians to have some prior knowledge of light-curing units before committed to purchasing one.

\section{REFERENCES}

1. Combe EC, Burke FJT, Douglas WH. Dental Biomaterials. 1st ed. Kluwer Academic Publisher. Boston/ Dordrecht/London 1999.

2. Brantley WA, Eliades T. Orthodontic Materials. Scientific and Clinical aspects. Thieme. 2001. Stuttgart.

3. Davidson CL, de Gee AJ. Light-curing units, polymerization, and clinical implications. J Adhesive Dent 2000; 2: 167-73.

4. Harrington E, Wilson HJ, Shortall AC. Lightactivated restorative materials: a method of determining effective radiation times. J Oral Rehabil 1996; 23: 210-8.

5. International Organization for standardization. ISO/TS 10650:1999. Dental equipment-powered polymerisation activators. Geneva, Switzerland: International organization for standardization; 1999.

6. International Organization for Standardization. ISO 4049:2000. Dentistry-polymer based filling, restorative and luting materials. 3rd ed. Geneva, Switzerland: International Organization for Standardization; 2000.

7. De Gee AJ, Ten Harkel-Hagenaar E, Davidson CL. Color dye for identification of completely cured composite resins. J Prosthet Dent 1984; 52: 626-31.

8. De Lange C, Baush JR, Davidson CL. The curing pattern of photo-initiated dental composites. J Oral Rehabil 1980; 7: 369-77.

9. Yearn JA. Factors affecting cure of visible light activated composites. Int Dent J 1985; 35: 21825 .

10. Rueggeberg FA, Caughman WF, Curtis JW, Davies HC. Factors affecting cure of depths within light activated resin composites. Am Dent J 1994; 6: 91-5.
11. Elipar ${ }^{\mathrm{TM}} 2500$ Halogen Curing Light ...http:// cms. $3 \mathrm{~m}$.com/cms/CA/en/2-21/kFeeiFY/ view.jhtml. (22 November 2004).

12. Instructions.http://cms.3m.com/cms/GB/en/2-21/ zRiiEL/view.jhtml. (22 November 2004).

13. Instructions. http://cms.3m.com/cms/CA/en/221/zRiiEL/view.jhtml. (22 November 2004).

14. Craig RG. Chemistry, composition, and properties of composite resins. Dent Clin North Am 191; 25: 219-39.

15. Lu RT. Photopolymerization of unsaturated polyester resin. Canadian patent 1,004,200.1977.

16. Read MJF. The bonding of orthodontic attachments using a visible light cured adhesive. Br. J Ortho1984; 11: 16-20.

17. O'Brien WJ. Dental Material and Their Selection. 3nd ed. Quintessence 2002.

18. Rueggeberg FA. From vulcanite to vinyl, a history of resins in restorative dentistry. J Prosthet Dent 2002; 87:364-79.

19. Rueggeberg FA. Contemporary issues in photo curing. Compend Contin Educ Dent 1999; 20(Suppl): S4-15.

20. Pettermerides AP, Ireland AJ, Sherriff M. An ex vivo investigation into the use of a Plasma arc lamp when using a visible light cured composite and a resin- modified Glass Poly (alkenoate) cement in orthodontic bonding. J Ortho 2001; 28: 237-44.

21. Sunna S, Rock WP. Clinical performance of orthodontic brackets and adhesive systems. Br J Orthod 1999; 26: 47-50.

22. Mehl A, Hickel R, Kunzelmann KH. Physical properties and gap formation of light cured composites with and without 'soft start polymerization'. J Dent 1997; 25: 321-30.

23. Bouschlicher MR, Rueggeberg FA, Boyer DB. Effect of stepped light intensity on polymerization force and conversion in a photoactivated composite. J Esthet Dent 2000; 12: 23-32.

24. Bouschlicher MR, Rueggeberg FA. Effect of ramped light intensity on polymerization force and conversion in a photoactivated composite. $\mathbf{J}$ Esthet Dent 2000; 12: 328-39. 
25. Mayes JH. Curing lights: An overview. Clinical Impressions 2001;10: 16-8.

26. Radzi Z, Wood DJ, Bubb N. A comparison of three different light curing units: An in vitro study. Proceeding British Orthodontic Conference 2002; P38: 53.

27. Power Slot TM. Fast curing optic guide. Reliance Orthodontics 2000.

28. Curtis JW, Rueggeberg FA, Lee AJ. Curing efficiency of the turbo tip. General Dentistry 1995; Sept/Oct: 428-33.

29. Frost T, Norevall LI, Persson M. Bond strength and clinical efficiency for two light guide sizes in orthodontic bracket bonding. Br J Orthod 1997; 24: 35-40.

30. Kelsey WP, Blankenau RJ, Powell GL, Barkmeier WW. Stormberg EF. Power and time requirements for use of the argon laser to polymerize the composite resins. J Clin laser Med Surg 1992; 10: 273-8.

31. Cacciafesta V, Sfodrini MF, Sfodrini G. A xenon arc light curing unit for bonding and bleaching. J Clin Ortho 2000; xxxiv: 94-6.

32. Nakamura S, Senoh M, Mukai T. Double Heterostructure blue-light emitting diodes. Japanese J of Applied Physics 1993; 32: L8-L11.

33. Swanson T, Dunn WJ. Childers DE, Taloumis LJ. Shear bond strength of orthodontic brackets bonded with light-emitting diode curing units at various polymerization times. Am J Orthod Dentofacial Orthop 2004; 125: 337-41.

34. Althoff $\mathrm{O}$, Hartung M. Advances in light curing. Am J Dent 2000; 13 (special issue): 77D-81D.

35. Mills RW, Jandt KD. Blue LEDs for curing polymer-based dental filling materials. OS NS(June) 1998.

36. Nomoto R. Effect of light wavelength on polymerization of light cured resins. Dent Mater 1997; 16: 60-73.

37. Cipolla AJ. Laser curing of photoactivated Restorative materials. 1993 Salt Lake: Utah; ILT Systems.

38. Hinoura K, Masashi M, Hideo O. Influence on argon laser curing on resin bonded strength. Am J Dent 1993; 6: 69-71.
39. Frentzen M, Koort HJ. Lasers in dentistry: new possibilities with advancing laser technology? Int Dent J 1990; 40: 323-32.

40. Kurchak M, Desantos B, Powers J, Turner D. Argon laser for light curing adhesives, J Clin Orthod 1997;XXXI: 371-4.

41. Birdsell DC, Bannon PJ, Webb RB. Harmful effect of near-ultra violet radiation used for polymerization of a sealant and a composite resin. J Am Dent Assoc1977: 94: 311-4.

42. Fujibayashi K, Ishimaru K, Kohno A. A study on light activation units using blue light emitting diodes. J Japan Dent Pres Acad 1996; 39: 1808.

43. Mills RW. Blue light emitting diodes- an alternative method of light curing. Br Dent $\mathbf{J}$ 1995; 178: 169.

44. Rueggeberg FA, Twiggs SW, Caughman WF, Khajotia S. Lifetime intensity profiles of 11 light curing units (abstract 2897) J Dent Res 1996; 75 : 380

45. Friedman J. Variability of lamp characteristics in dental curing lights. J Esthet Dent 1989; 1: 189-90.

46. Birnie DJ. Bonding and debonding. Excellence in Orthodontics 2002. London.

47. Bishara SE, VonWald L, Laffoon JE. Standard versus turbo light guides and their effects the shear bond strength of an orthodontic adhesive. World J Ortho 2001; 2: 154-8.

48. Hannig $M$, Bott $B$. In vitro pulp chamber temperature rise during composite resin polymerization with various light curing sources. Dent Mat 1999; 15: 275-81.

49. Bouschlicher MR, Whalen SR, Dawson DV. Intrapulpal temperature increases with LED, QTH and Plasma arc photoinitiation. J Dent Res 2002; 81: Abstract 0510 (A-89).

50. Zach L, Cohen J. Pulp response to externally applied heat. Oral Surg Oral Med Oral Path 1965; 19: 515-30.

51. Oesterle LJ, Newman SM, Shellhart WC. Rapid curing of bonding composite with a xenon plasma arc light. Am J Orthod Dentofacial Orthop 2001; 119: 610-6. 
52. Rea MS. Lighting Handbook: Reference and application. $8^{\text {th }}$ ed. New York: Illuminating Engineering Society of North America. 1993: 237-40.

53. Blankenau RJ, Kelsey WP, Powell GL, Shearer GO, Barkmeier WW, Cavel WT. Degree of composite resin polymerization with visible light and argon laser. Am J Dent 1991; 4: 40-2.

54. Kelsey WP, Blankenau RJ, Powell GL, Barkmeier WW, Cavel WT, Whissenant BK. Enhancement of physical properties of resin restorative materials by laser polymerization. Lasers Surgical Medicine 1989; 9: 623-7.

55. Powell GL, Kelsey WP, Blankenau RJ, Barkmeier WW. The use of an argon laser for polymerization of composite resin. J Esthet Dent 1989; 1: 34-7.

56. Severin C, Maquin M. Argon ion laser beam as composite light curing agent; In Laser in dentistry. New York. Elsevier. 1989; 241-6.

57. Powell GL, Morton TH, Whissenant BK. Argon laser oral safety parameters for teeth. Lasers Surgical Medicine 1993; 13: 548-52.

58. Reynold IR. A review of direct orthodontic bonding. Br J Orthod 1975; 2; 171-8.

59. Dunn WJ, Bush AC. A comparison of polymerisation by light emitting diode and halogen based light curing units. J Am Dent Assoc 2002; 133: 335-41.

60. Usumez S, Buyyukyilmaz T, Karaman AI. Effect of light emitting diode on bond strength of orthodontic brackets. Angle Orthod 2004; 74 : 259-63.

61. Evans LJ, Peters C, Flickinger C, Taloumis, Dunn W. A comparison of shear bond strengths of orthodontic brackets using various light sources, light guides, and cure times. Am J Orthod Dentofacial Orthop 2002; 121: 510-5.

62. Ishikawa H, Komari, Kojima Ando F. Orthodontic bracket bonding with a plasma arc light and resin reinforced glass ionomer cement. Am J Orthod Dentofacial Orthop 2001; 120: 5863.

63. Oesterle LJ, Newman SM, Shellhart WC. Comparative bond strength of brackets cured using pulsed xenon curing light with 2 different light guide sizes. Am J Orthod Dentofacial Orthop 2002; 122: 242-50.
64. Sfondrini MF, Cacciafesta V, Pistorio S, Sfondrini G. Effects of conventional and high intensity light curing on enamel shear bond strength of composite resin and resin modified glass ionomer. Am J Orthod Dentofacial Orthop 2001; 119: $30-5$.

65. Eitzen CJ, Caputo AA, Moon HB. Bond strength of plasma arc light emitting diode cured orthodontic adhesives. J Dent Res 2002 81; Abstract 1159.

66. Sfondrini MF, Cacciafesta V, Klersy C. Halogen versus high intensity light curing of uncoated and precoated brackets: ashear bond strength study. J Orthod 2002; 29: 45-50.

67. James JW, Miller BH, English JD, Tadlock LP, Bushchang PH. Effect of high speed curing device on shear bond strength and microleakage of orthodontic brackets. Am J Orthod Dentofacial Orthop 2003; 123: 555-61.

68. Ip TB, Rock WP. A comparison of three light curing units for bonding adhesive pre-coated brackets. J Orthod 2004; 31: 243-7.

69. Cacciafesta V, Sfondrini MF, Scribante A. Plasma arc versus halogen light curing of adhesive: A 12 month clinical study of bond failure. Am J Orthod Dentofacial Orthop 2004; 126:194-9.

70. Dunn WJ, Taloumis 1T. Polymerisation of bonding composite with light emitting diode (LED) curing units. Am J Orthod Dentofacial Orthop 2002; 122: 236-41.

71. Talbot TQ, Blankenau RJ, Zobitz ME, Weaver AL, Lohse M, Robellato J. Effect of argon laser irradiation on shear bond strength of orthodontic brackets: An in vitro study. Am J Orthod Dentofacial Orthop 2000; 118: 274-9.

72. Lalani N, Foley TF, Voth R, Banting D, Mamandras A. Polymerization with the argon laser: curing time and shear bond strength. Angle Orthod 2000; 70: 28-33.

73. Weinberger SJ, Foley TF, McConnell RJ, Wright GZ. Bond strength of two ceramic brackets using argon laser, light and chemically cured resin systems. Angle Orthod 1997; 67:173-8.

74. Husson MV. An in vitro evaluation of argon laser cured bond strengths of orthodontic brackets. Am J Orthod Dentofacial Orthop 2000; 118: 362 . 
75. Caughman WG, Rueggeberg FA, Curtis JW. Clinical guidelines for photocuring restorative resins. J Am Dent Assoc 1995; 126: $1280-5$.

76. Masutani S, Matsuzaki T, Akiyama Y. Study on light cured composite resins: consideration of continous volumetric shringkage of resins during light irradiation. J Jpn Conserv Dent. 1989; 32: 1605-11.

77. Barghi N, Berry T, Hatton C. Evaluating intensity output of curing units in private dental offices. J Am Dent Assoc 1994; 125: 992-6.

78. Miyazaki M, Hattori T, Ichiishi Y, Kondo M, Onose H, Moore BK. Evaluation of curing units used in private dental offices. Oper Dent 1998; 23: $50-4$.

79. Pickett KL, Sadowsky PL, Jacobsen A, Lacefield W. Orthodontic in vivo bond strength: comparison with in vitro results. Angle Orthod; 71: $141-8$.

80. Fox NA, McCabe JF, Buckley JG. A critique of bond strength testing in orthodontics. Br J Orthod 1994; 21: 33-43.

81. Eliades GC, Brantley WA. The inappropriateness of conventional orthodontic bond strength assessment protocols. Eur J Orthod 2000; 22: 13-23.

82. Van Noort R, Noorozi S, Howard IC, Cardew G. A critique of bond strength measurements. $\mathrm{J}$ Dentistry 1989; 17: 61-7.

83. Powers JM, Kim HB, Turner DS. Orthodontic adhesives and bond strength testing. Sem Orthod 1997; 3: 147-56.

84. Stanford SK, Wozniak WT, Fan PL. The need for standardization of test protocols. Sem Orthod 1997; 3: 206-9.

85. International Standards organization. Dental materials-Guidance on testing adhesion to tooth structure. ISO 106/SC 1/WG 11.
86. Banerjee A. Medical statistics made clear. An introduction to basic concepts. The Royal Society of Medicine Press. 2003. London.

87. Fan PL, Schumacher RM, Azzolin K, Geary R, Eichmiller FC. Curing light intensity and depth of cure of resin based composites tested according to international standards. J Am Dent Assoc. 2002; 133: 429-34.

88. Davidson-Kaban SS, Davidson CL, Feilzer AJ, de Gee AJ, Erdilek N. The effect of curing light variations on bulk curing and wall to wall quality of two types and various shades of resin composites. Dent Mater 1997; 13: 344-52.

89. Sakaguchi RL, Peters MCRB, Nelson SR, Douglas WH, Poort HW. Effect of polymerisation contraction composite restorations. J Dentistry 1992; 20: 178-82.

90. Sakaguchi RL, Douglas WH, Peters MCRB. Curing light performance and polymerisation of composite restorative materials. J Dentistry 1992, 20: 183-8.

91. Rueggeberg FA, Caughman WF. Effect of light tip distance on polymerization for resin composite. Int J Prosthod 1993; 6: 364-70.

92. Rueggeberg FA, Caughman WF, Curtis JW, Davies HC. A predictive model for polymerization of photo-activated resin composites. Int J Prosthod 1994; 7: 159-66.

93. Rueggeberg FA, Caughman WF, Curtis JW. Effect of light intensity and exposure duration on cure of resin composites. Oper Dent 1994; 19: 26-32.

94. Yunus N, Harrison A, Huggert R. Effect of microwave irradiation on the flexural strength and residual monomer levels of an acrylic resin repair material. J Oral Rehabil 1994; 21: 6418. 